Canadian University Music Review

Canadian University Music Review

Revue de musique des universités canadiennes

\title{
Dérives, No 44-45, 1984, "Musique contemporaine au Québec », sous la direction de Marcelle Guertin, 156 pages ill., et un disque 33 t., $17 \mathrm{~cm}$
}

\section{Marie-Thérèse Lefebvre}

\section{Numéro 6, 1985}

URI : https://id.erudit.org/iderudit/1014075ar

DOI : https://doi.org/10.7202/1014075ar

Aller au sommaire du numéro

\section{Éditeur(s)}

Canadian University Music Society / Société de musique des universités canadiennes

\section{ISSN}

0710-0353 (imprimé)

2291-2436 (numérique)

Découvrir la revue

Citer ce compte rendu

Lefebvre, M.-T. (1985). Compte rendu de [Dérives, No 44-45, 1984, « Musique contemporaine au Québec », sous la direction de Marcelle Guertin, 156 pages ill., et un disque 33 t., $17 \mathrm{~cm}$. Canadian University Music Review / Revue de musique des universités canadiennes, (6), 339-340. https://doi.org/10.7202/1014075ar

(c) Canadian University Music Society / Société de musique des universités canadiennes, 1985
Ce document est protégé par la loi sur le droit d'auteur. L’utilisation des services d'Érudit (y compris la reproduction) est assujettie à sa politique d'utilisation que vous pouvez consulter en ligne.

https://apropos.erudit.org/fr/usagers/politique-dutilisation/ 
années de l'Orchestre Symphonique de Montréal et ce, dans la mesure où l'on veut bien se laisser raconter une belle histoire de coeur!

Claire Rhéaume

DÉRIVES, No 44-45, 1984, " Musique contemporaine au Québec », sous la direction de Marcelle Guertin, 156 pages ill., et un disque $33 \mathrm{t}$., $17 \mathrm{~cm}$.

À l'occasion des Journées mondiales de la musique organisées par la S.I.M.C. en octobre 1984 à Montréal, la revue Dérives publie un numéro spécial consacré à l'étude des divers aspects de la musique contemporaine au Québec ; un disque reproduisant des extraits de "Lignes et points " (1964) de Pierre Mercure et de "Lonely Child " (1980) de Claude Vivier accompagne ce numéro. Cet ensemble d'articles ne prétend pas apporter des faits nouveaux à caractère historique sur ce sujet, mais se présente sous forme de bilan et offre une vue d'ensemble de la multiplicité des tendances actuelles. Compte tenu que nos derniers " bilans " historiques datent de 1964 (Lásalle-Leduc, A., La vie musicale au Canada français) et de 1971 (Duguay, R., Musiques du Kébek), ce numéro de Dérives comble donc une lacune importante au niveau de l'information. La présentation de points de vue différents exprimés par une variété d'intervenants du monde musical sur notre musique " telle que rêvée, composée, interprétée, diffusée et reçue " permet au lecteur de saisir cette réalité à la fois complexe et méconnue.

Parmi les onze articles proposés, huit présentent un caractère inédit ; la présentation de Marcelle Guertin confronte le lecteur aux multiples résonnances du terme " contemporain ", alors que les commentaires des compositeurs Garant et Tremblay démontrent la perpétuelle remise en question des créateurs ; il est d'ailleurs intéressant, à ce propos, de lire immédiatement après, les réflexions du jeune compositeur Michel Gonneville, pour observer les points de convergence et la "différence pacifique " entre ces deux générations.

Les interrogations sur le théâtre musical présentées par Gisèle Ricard, sous forme d'aventure biographique dans un style piquant et humoristique, trouvent une certaine complémentarité dans les commentaires de Micheline Coulombe-Saint-Marcoux sur son oeuvre Transit (dernier écrit de cette compositrice, décédée en février 1985), rapportés par Jean Jonassaint.

À cause de la rareté des écrits des interprètes sur les problèmes d'interprétation de la musique contemporaine, l'article de Marcelle Guertin et de Javier Garcia Mendez réalisé à partir d'échanges informels avec Lorraine Vaillancourt, elle-même interprète très appréciée du public des Événements du Neuf et de l'Atelier de musique contemporaine de la Faculté de musique de l'Université de Montréal, est peut-être celui qui éclaire le plus le lecteur sur le renouveau musical qu'ont proposé les 
interprètes à travers leur vision nouvelle des oeuvres de Debussy jusqu'aux oeuvres les plus récentes.

Enfin, l'article de Carol Bergeron soulève l'épineux problème (d'une façon trop courte à mon avis) de la critique musicale ; s'il est vrai, comme le souligne l'auteur, qu'il est difficile " de juger de la valeur intrinsèque des oeuvres nouvelles " (ce qui, à mon avis n'est pas son rôle, on se moque des jugements personnels des Claude Gingras et des Eric McLean), il précise qu'une information " plus objective et » a priori " demeure la seule valable.

Par contre, les articles de François Guérin sur les musiques électroacoustiques au Québec, de Mireille Gagné présentant un panorama des années 50 et les sources d'inspiration extra-musicales de quelques compositeurs et de Robert Léonard sur la recherche en animation musicale sont moins innovateurs ; d'une part, bien que présentés différemment, ils ont déjà fait l'objet de publications ou d'études antérieures et il aurait été important d'en mentionner les sources. ${ }^{1}$

D'autre part, l'emphase mise sur le rôle de Pierre Mercure, « l'un des plus ardents défenseurs de musiques nouvelles » par François Guérin (qui a oublié de citer le Nucléogame (1955) de Garant, considérée comme première oeuvre mixte) et par Mireille Gagné qui ajoute : "comme membre du groupe [automatiste], Mercure a su faire évoluer la notion d'oeuvre esthétique en faisant éclater ses limites ", ne va pas plus loin que ce qu'on en disait en 1971 et ne repose malheureusement sur aucune étude systématique de cette époque.

Cette observation ne cherche pas à jeter le discrédit sur ces articles, qui par le caractère " panoramique " permettent au lecteur non initié de Dérives de mieux comprendre les articles précédents, tout comme l'article de Robert Léonard qui nous informe d'une activité pédagogique originale peut connue du public. Ce que je tente de souligner par ce commentaire, c'est l'urgence de se pencher de façon beaucoup plus approfondie sur les origines de cette " modernité " qui apparaît au Québec autour des années 50 (et peut-être même avant), afin que cette étude puisse s'intégrer aux recherches plus globales qui se font actuellement sur l'histoire culturelle du Québec, lesquelles n'en ont rapporté jusqu'à présent que les aspects folkloriques ou populaires ignorant complètement la musique savante.

Marie-Thérèse Lefebvre

\section{NOTE}

1. Voir notamment : GUERIN, F., Les musiques électroacoustiques. À l'écoute de la musique d'ici, série 2, C.M.C., Montréal, 1983 ; GAGNÉ, M., Les sources d'inspiration extra-musicales de quelques compositeurs québécois, Mémoire de maîtrise, Faculté de musique, Université de Montréal, 1981 ; LÉONARD, R., 14 jeux sonores, GRAM 1980-81, Faculté de musique, Université de Montréal. 